\title{
Practice of the Volunteer Education with Enforcement of the Nursing-Care Prevention
}

\author{
Takaharu KURODA*, Teruyoshi DAITOH** and Ginsuke KONO* \\ *Department of mechanical Engineering, Kisarazu National College of Technology \\ 2-11-1 Kiyomidaihigashi, Kiasrazu-shi, Chiba, Japan \\ E-mail: kuroda@kisarazu.ac.jp \\ ** Depatment of mechanical and electronic Engineering, Salesian Polytechnic \\ 4-6-8, Oyamagaoka, Machida-city, Tokyo, Japan
}

\begin{abstract}
In Japan, the population of elderly, who are at age of 65 and over, is estimated to be about 36million in 2050 . This number is one-third of the total population, which indicates the coming of hyper elderly society. Such situation becomes the big financial burden by the increase of the medical cost. This paper describes the nursing-care prevention classes cooperated with Kisarazu city.

Furthermore, this report examined the educational effects on the students who voluntary participated in the nursing-care classes.
\end{abstract}

Key words: Nursing-Care Prevention, Regional Cooperation, Advanced Age, Arrangement of the Balance of the Body, Educational Effect

\section{Introduction}

In Japan, the population of elderly, who are at age of 65 and over, is estimated to be about 36million in 2050. This number is one-third of the total population, which indicates the coming of hyper elderly society(1). It has been 9 years since the Nursing-care welfare system started, in April, 2000. Number of people who use the system has raised $200 \%$ compared to the previous year, which resulting the budget also raised more than $200 \%$.

Given this circumstance, demands for support to people with many kind of handicap are growing, and hope for industrial structure to understand and support them is also increasing. Therefore, this nursing-care prevention is an essential education to the next generation of engineers.

Fortunately, Kisarazu-city has been researching the nursing-care prevention classes in order to reduce the medical expense, since 2005, as well as offered us to cooperate with them.

We already have announced the contents and the evaluation of the nursing-care classes in the previous studies (2), (3). This report examined the educational effects on the students who voluntary participated in the nursing-care classes. Students, who have been researching biomechanics through the 3 years of the nursing-care prevention classes, participated to the classes. We conducted surveys and analyzed to recognize their willingness and educational effects on them.

\section{About the Nursing-care prevention class}

There are Nursing-care prevention classes twice a year. A two-hour class is held once a week for 15 weeks. A recruitment of applicants was conducted by public information of 
Kisarazu city one month before the class begins.

The contents of the 15 weeks are:

1 st week-Lecture of the balance rehabilitation and chiropractic(4), (5).

2nd week- Medical examination of the applicants who understand the aim of the class at Asunaro Keiai clinic.

3rd week- Physical fitness tests of the participants.

The 4th paragraph explains the contents of the fitness test. The test was also held in the middle and at the end of the trimester. Thus, the actual number rehabilitation for nursing-care prevention class was 10 weeks.

Applicants to the classes are restricted to people who are at the age of 65 or more, as well as not in need of care to spend daily life. The number of the participants varies every year, but the total of 70 people ( $22 \mathrm{males}, 48 \mathrm{females}$ ) participated by now. Every year, 5 to 7 students from the fifth-year, and 2 to 4 students who major in nursing-care participated to these classes.

\section{Variation of rehabilitation examined}

Variety of rehabilitation methods that were examined in this class, are listed below.

1) Balance board and exercise ball training.

In balance board training, a participant stands on a board with its bottom is cone shaped, and keeps the balance.

In exercise ball training, a participant sits on a rubber ball, keeps the legs off the ground, and tries to stay with that position. This training aims to strengthen abdominal muscle and back muscle.

2) Erector spine training.

As the figure 1 shows, Two people perform erector spine training. The participant leans on the chiropractic table with adjustable angle. The partner pulls the arms of the participant. The participant stands without bending the waist to strengthen the erector spine. The participants are able to gain the muscle required to keep the balance when walking. This is the only muscle training in this class.

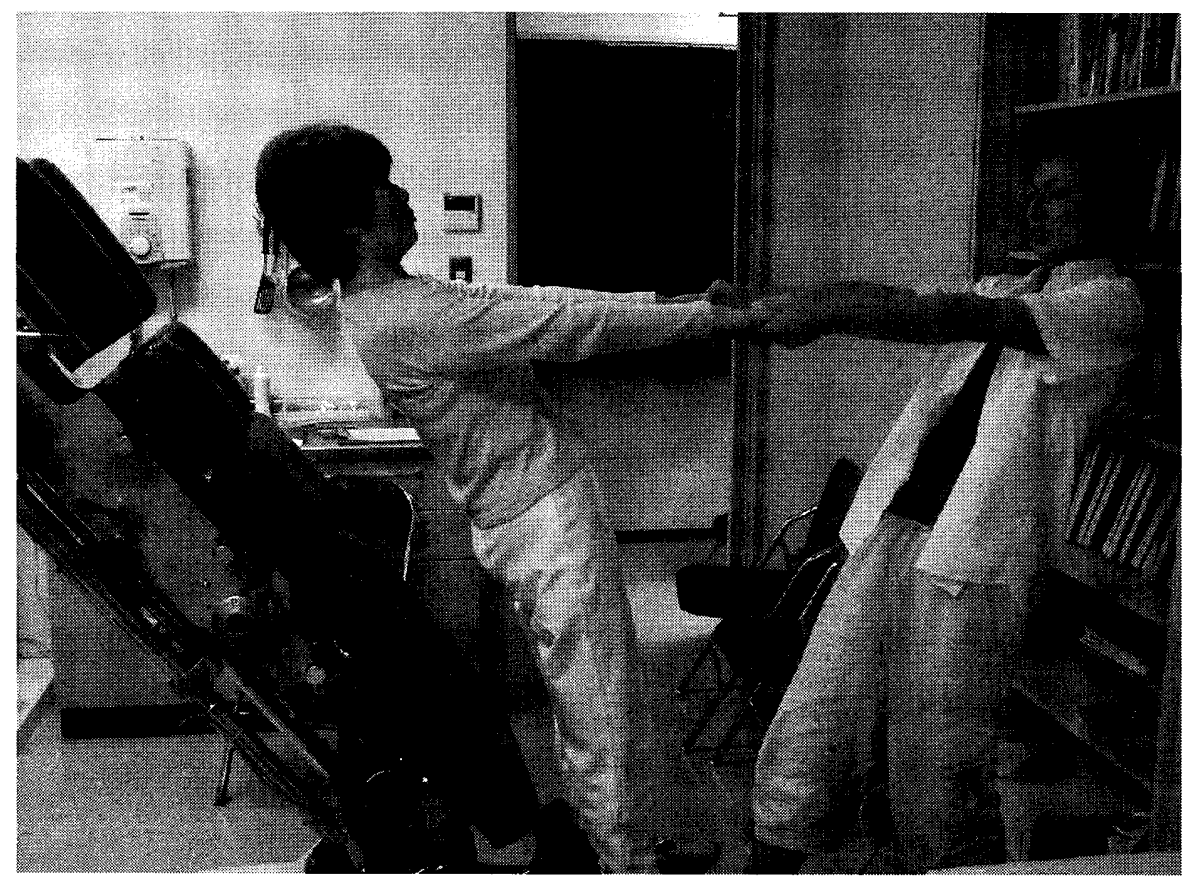

Fig.1 Erector spine training 
3) Masai Barefoot Technology (MBT) shoes training This training co-ordinate the body balance of the participants, by wearing the MBT shoes (shown in figure 2), and let them walk with the correct motion.

4) Palpation and chiropractic treatment.

A chiropractor asks questions to the participants and actually palpate and adjust the musculoskeletal system. A chiropractor mainly palpates muscles around waist, back and extremities, in order to treat them to co-ordinate the muscular balance.

5) Treatment using the Spinal Adjuster YP-412.

In order to adjust the joints (such as cervical vertebrae, thoracic vertebrae, lumber vertebrae and sacrum) that have abnormal mobility, the chiropractor treats using the spinal adjuster YP-412.

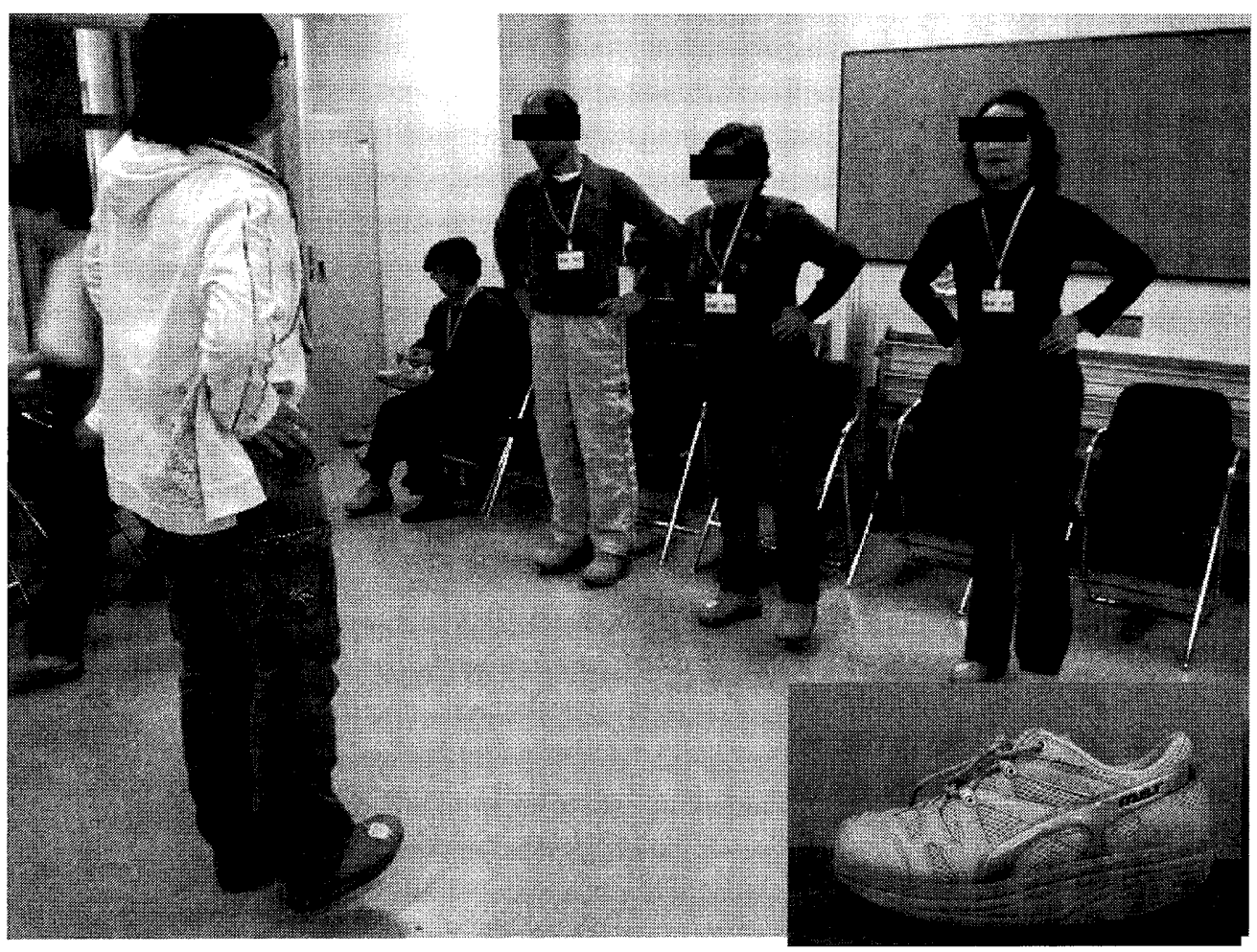

Fig.2 Masai Barefoot Technology (MBT) shoes training

\section{Test contents and methods}

1) Grip strength

Use a hand dynamometer to test both the right hand, and left hand.

2) $10 \mathrm{M}$ walking

Walk straight for $10 \mathrm{M}$ and note the time.

3) Single leg standing

Note how long a subject is able to stand on single leg. The test is undertaken both with eyes open, and eyes closed.

4) Muscle force of extensor and flexor of knee.

Note the muscular force when a subject extend the knees, and bend the knees using Manual Muscle Testing (NIHON MEDIX Co.).

5) Functional reach test

Raise the arms straight to the shoulder level, and reach forward. Note how much a 
subject is able to reach without falling down.

6) Long sitting functional test

The participant sits on a floor with the legs straight, back on a wall, arms straight up to the forward. Note how much length he/she is able to bend forward from that position.

7) Timed up \& go

Note the time starting from a subject sitting on a chair with armrest, stand from it, walk for $3 \mathrm{M}$ and come back down on the chair.

8) Foot pressure distribution

We used the "Footview" (Nitta Co.) to measure foot pressure distribution. Ordinary, it shows the movement of weight shift, pressure focus points of foot sole. However, this report only measures the foot pressure of the participants when standing.

\section{Results and analysis}

\subsection{Results}

This paragraph explains the results of year 2006(1st trimester- 9 participants, average of 70.7 years old. 2nd trimester- 10 participants, average of 69.7 years old) as an example.

Figure 3 shows the $10 \mathrm{~m}$ walking results. The participants were tested on the first day, at the middle, and the last day of the class. The figure shows that the time got shorter, in the both trimester.

Figure 4 shows the result of Time up \& go. The time got shorter in both "Kur". Figure 5 shows the results of knee flexibility. The graph shows the flexibility has improved. This is assumed that muscle force of extensor and flexor has enhanced by the erector spine training.

These results prove the ability of walking has increased by coordinating the muscle balance, even though a rehabilitation of actual "walking" has not been done.

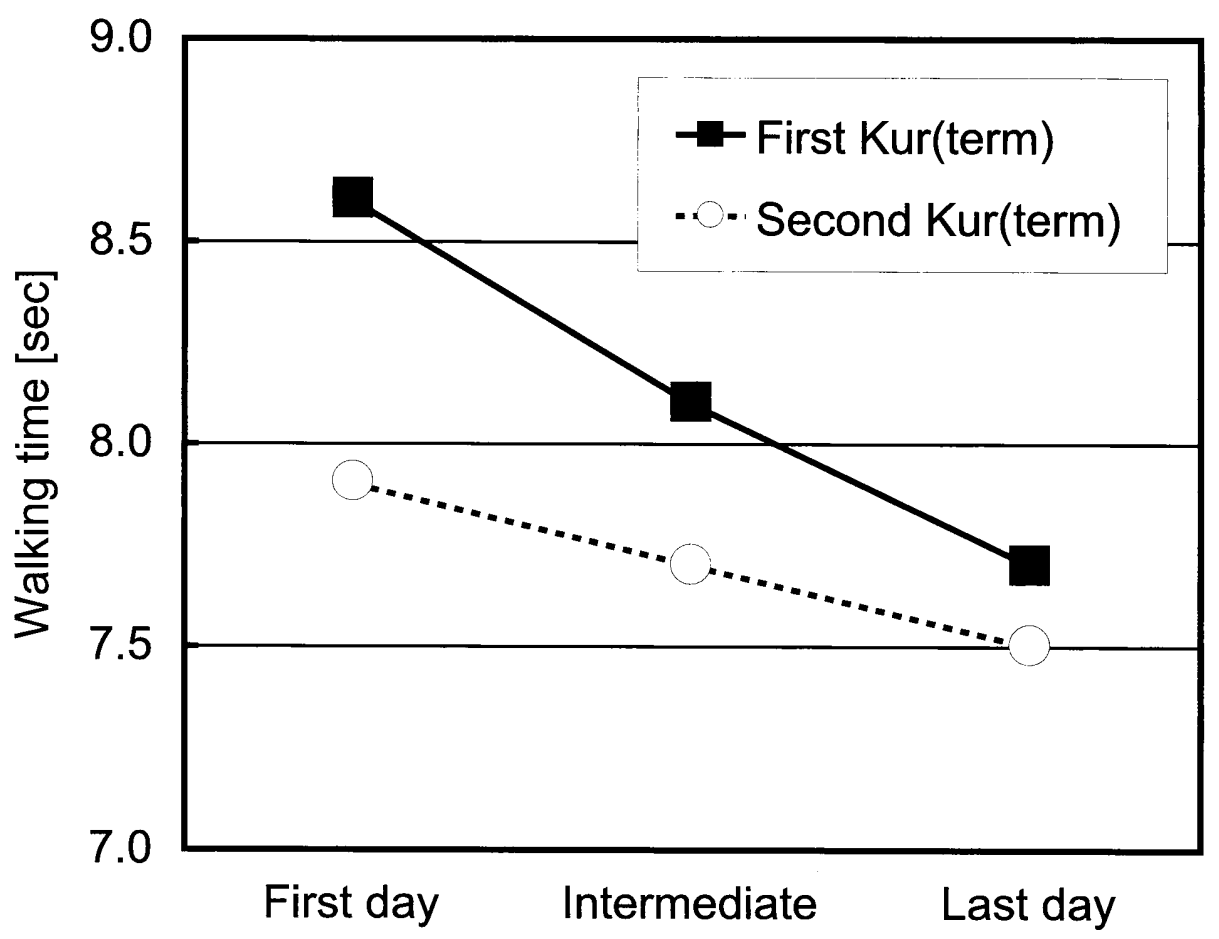

Fig. $310 \mathrm{~m}$ walking results 


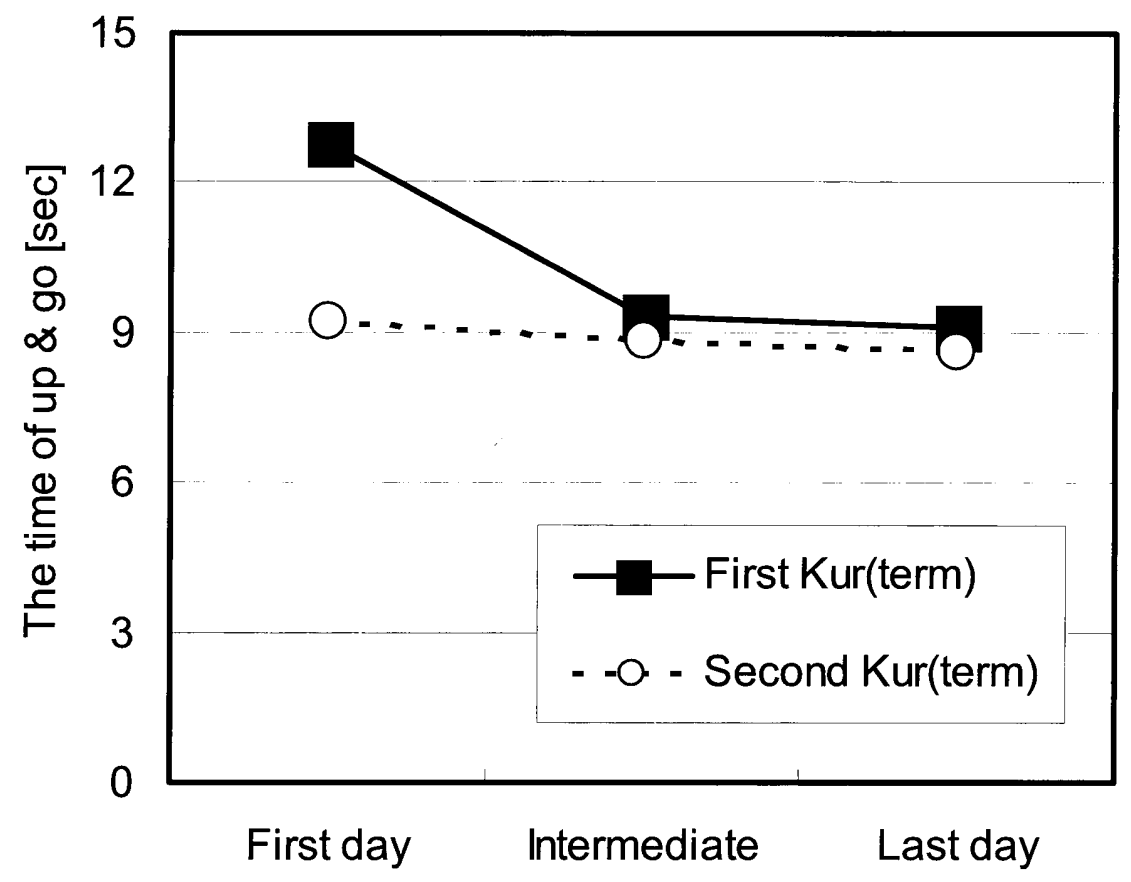

Fig.4 Time up \& go

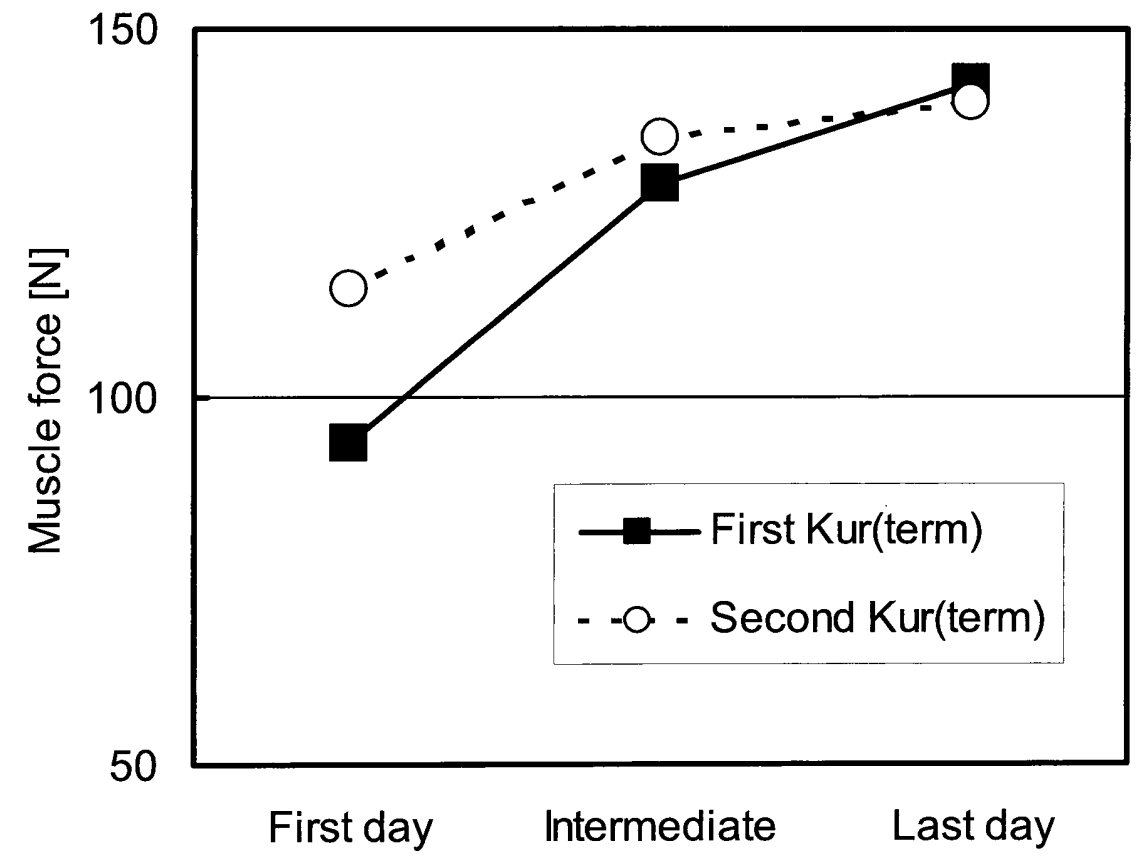

Fig.5 Muscle force of extensor and flexor of knee

An example of the foot pressure distribution result is shown in figure 6. Foot pressure is measured when a participant standing on a measuring matt with the change of color. The Fig.(a) shows the pressure distribution on the first day of the class. It shows that the both foot pressure is concentrated on the heel. The Fig.(b) shows the pressure distribution of the same participant on the last day of the class. It shows the foot pressure is distributed throughout the whole foot-sole including the toes, which indicates the balance has been adjusted. 

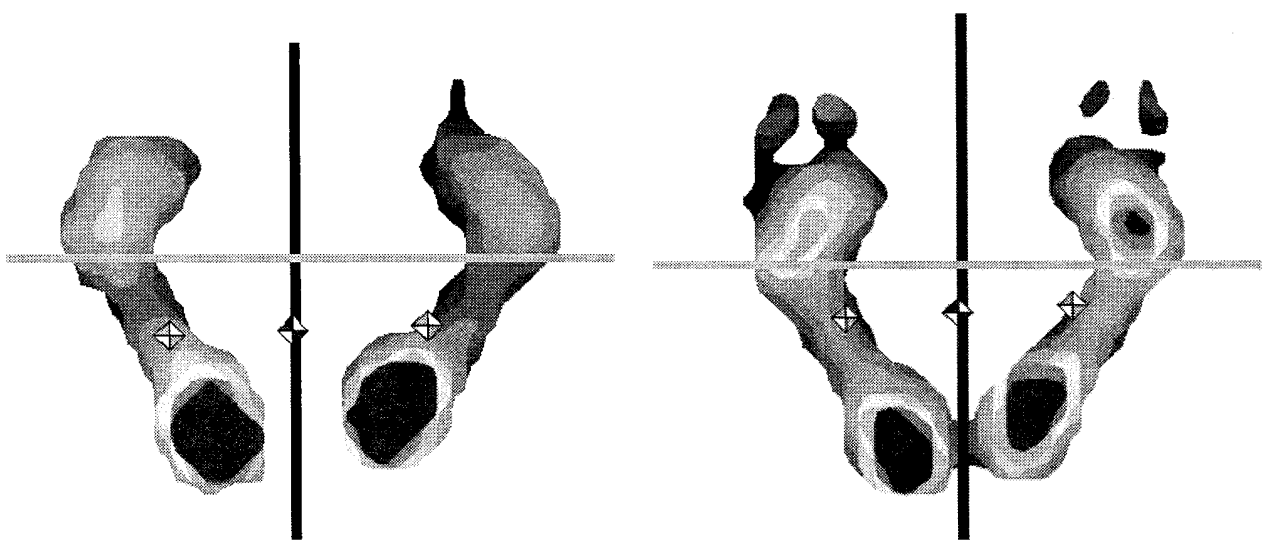

Fig.6 An example of the foot pressure distribution result

\subsection{Questionnaire results of the students}

This nursing-care class has been operated for 3years with the help of 19 students. We conducted a survey to these students. 18 out of the 19 students co-operated to the survey.

Figure 7 shows the results of motivation to the nursing-care prevention class. Figure 8 shows the attendance. Here, the evaluation is according to five of the following.

1: Negative (Passive)

2: A little negative (A little passive)

3: Neither (None)

4: A little positive (A little active)

5: Positive (Active)

The motivation is self-evaluated by the scale of 5 . The average motivation is roughly 4 , and average attendance is 4.8 . This shows that most students willingly participated to the classes.

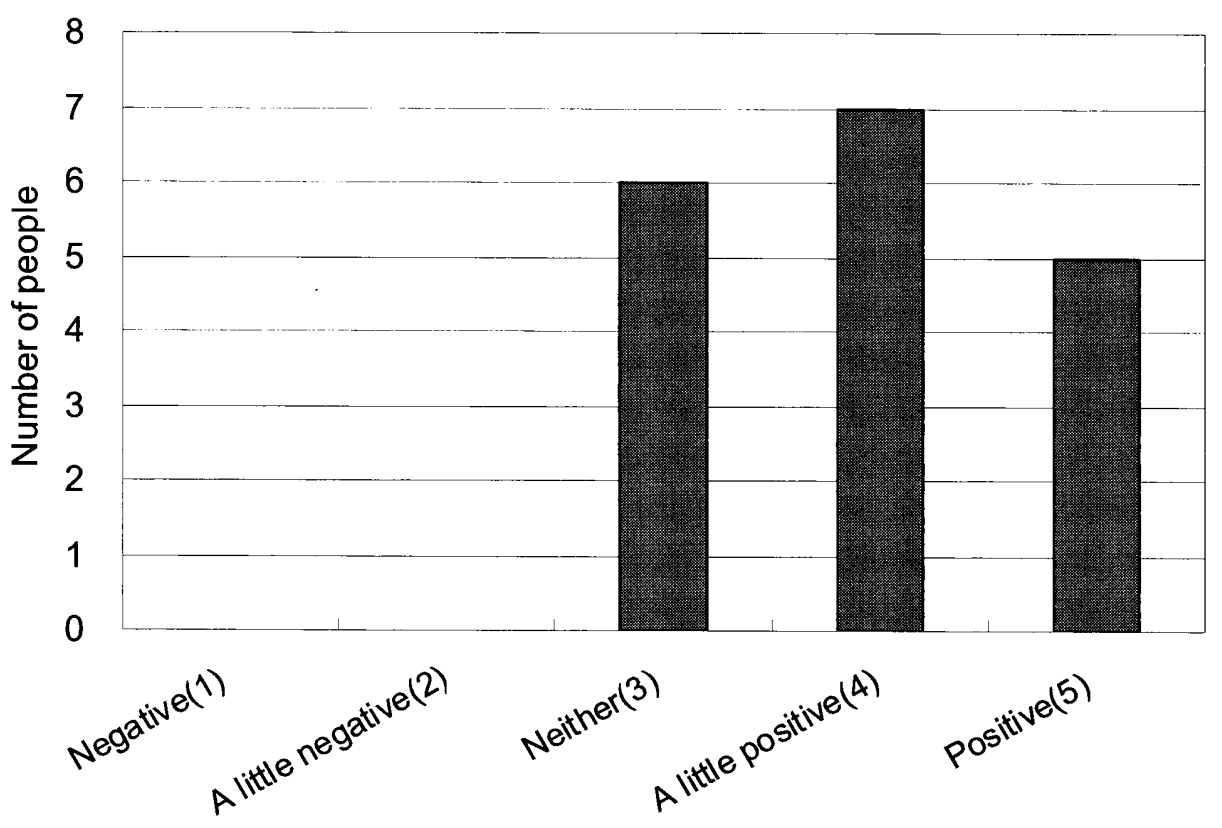

Fig.7 The motivation to the nursing-care prevention class 
Figure 9 shows the recognition of nursing-care. The average is high at 4.5 out of the scale of 5 . In addition, figure 10 shows the recognition of the students for elderly people. The answer of "recognition got deep" occupies the high ratio. Figure 11 shows the result of a question did the impression of the students and of the school get better? The figure indicates that the communication between the elderly and the students improved, which resulted in positive impression. Actual comments given to the students volunteered are listed below.

1) I now have the knowledge of nursing-care, and my consciousness to nursing-care also raised.

2) Physical ability of the aged people goes down. But, there are methods to improve the ability of elderly.

3) I now know that a body balance is a really important element to an exercise function.

4) I spent a worthwhile time with elderly that I cannot normally spend time with.

5) It was a good tool to improve the communication with the locals, and to know how elderly feel.

6) Elderly have a strong interest on their health.

7) I realized that things I can do easily such as walking on a little step, are difficult for elderly.

8) I realized the importance of a research participating with the local society.

These survey results show the students learned through the nursing-care class, not only the treatment of the exercise function of the elderly but also the "communication skill", "actual situation of elderly society" and "importance of research that is required by society", which are vital to be a technical professional.

Furthermore, we successfully promote positive impression of the Kisarazu National College of Technology and its students to the local elderly.

Below are the comments to a survey question "How did you find the students and their correspondence?" from the elderly who participated to the nursing-care class.

1) Very good

2) Good with kindness

3) They are extrovert and comfortable.

4) Great students!

5) I talked with them and know that they think about their future well, too.

6) They worked hard.

7) Happy that they always kept their smile.

8) They gave me positive spirit.

9) I appreciate their enthusiasm even during the summer holiday.

10) Very kind!

By reading the comments, we think that positive impression of high technology student to the elderly increased. 


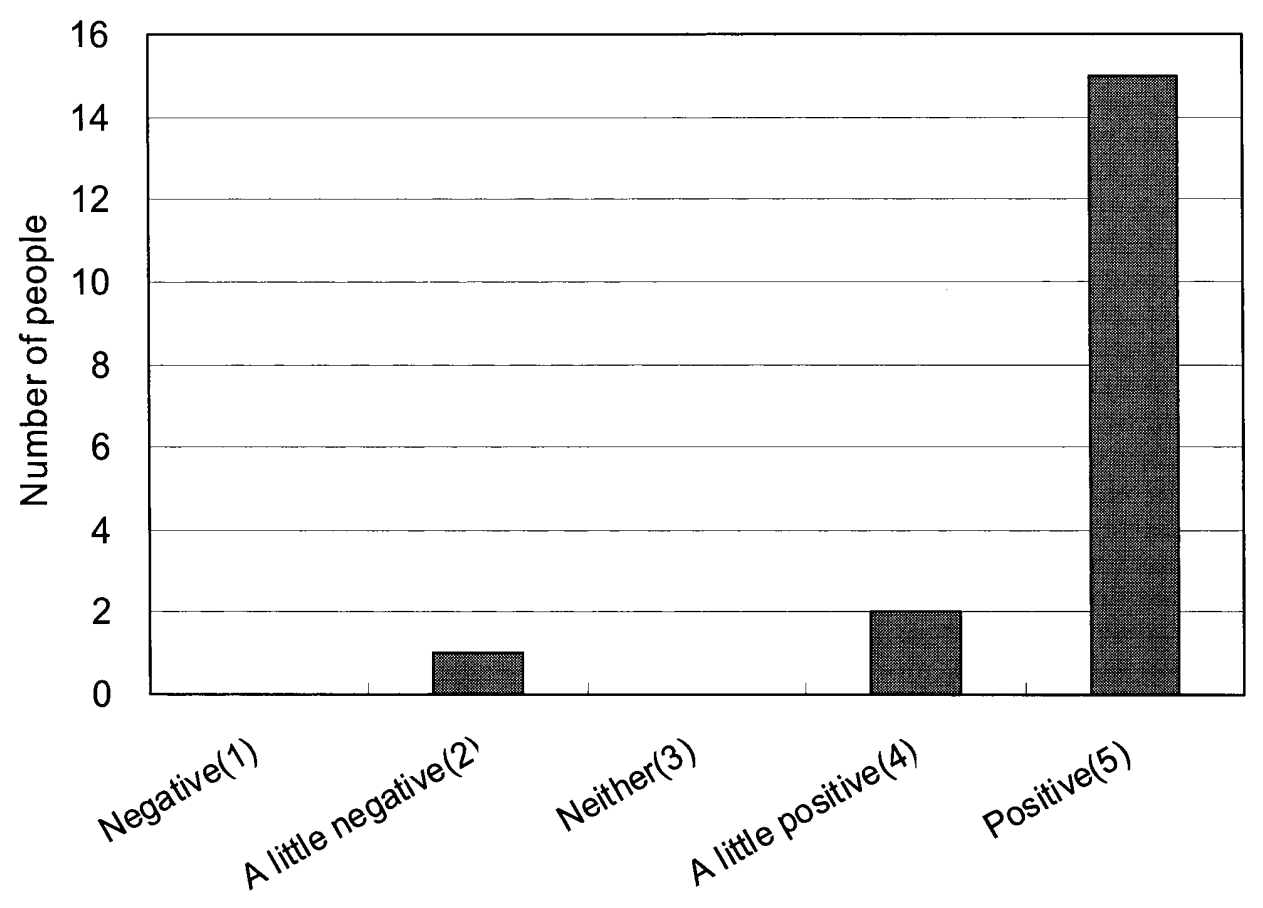

Fig. 8 The attendance situation

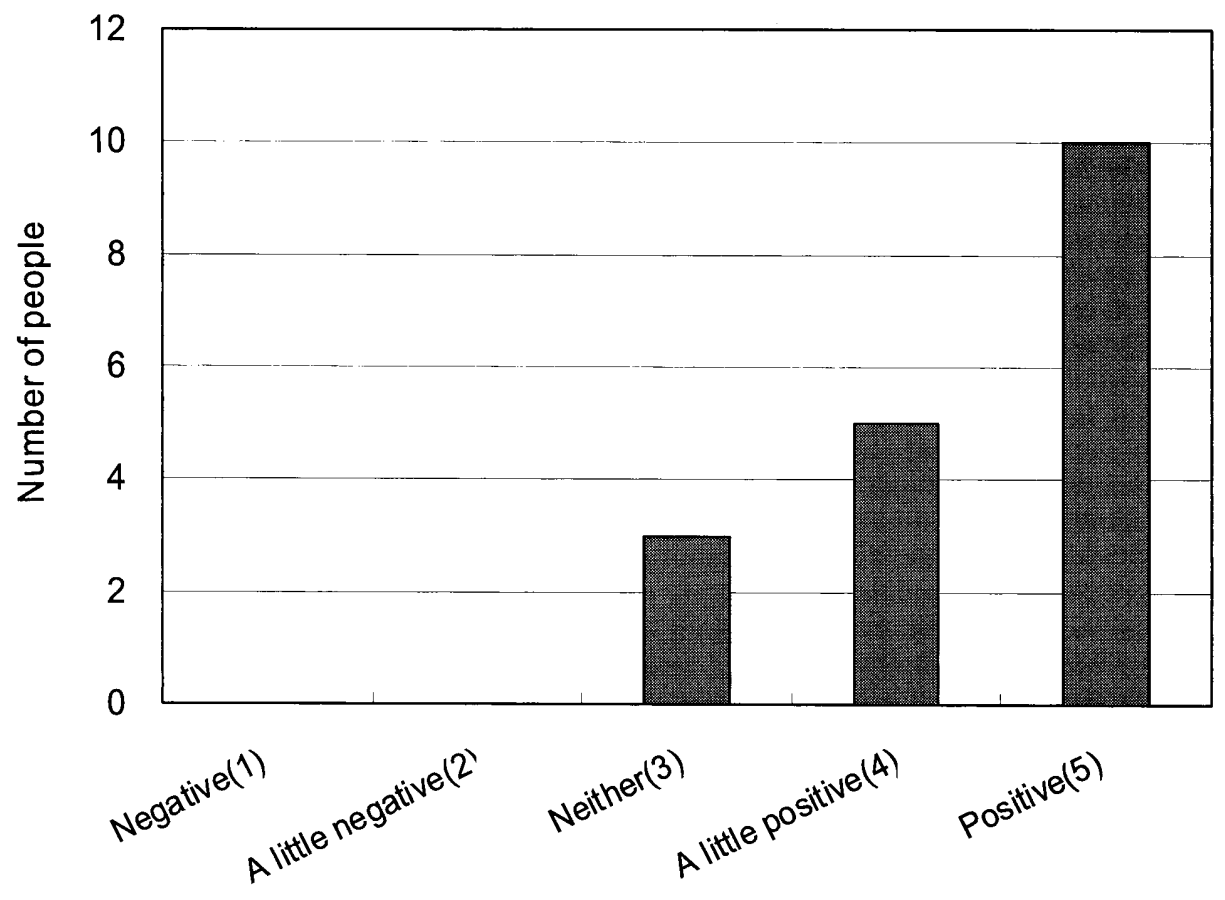

Fig.9 The recognition of nursing-care after the prevention classes 


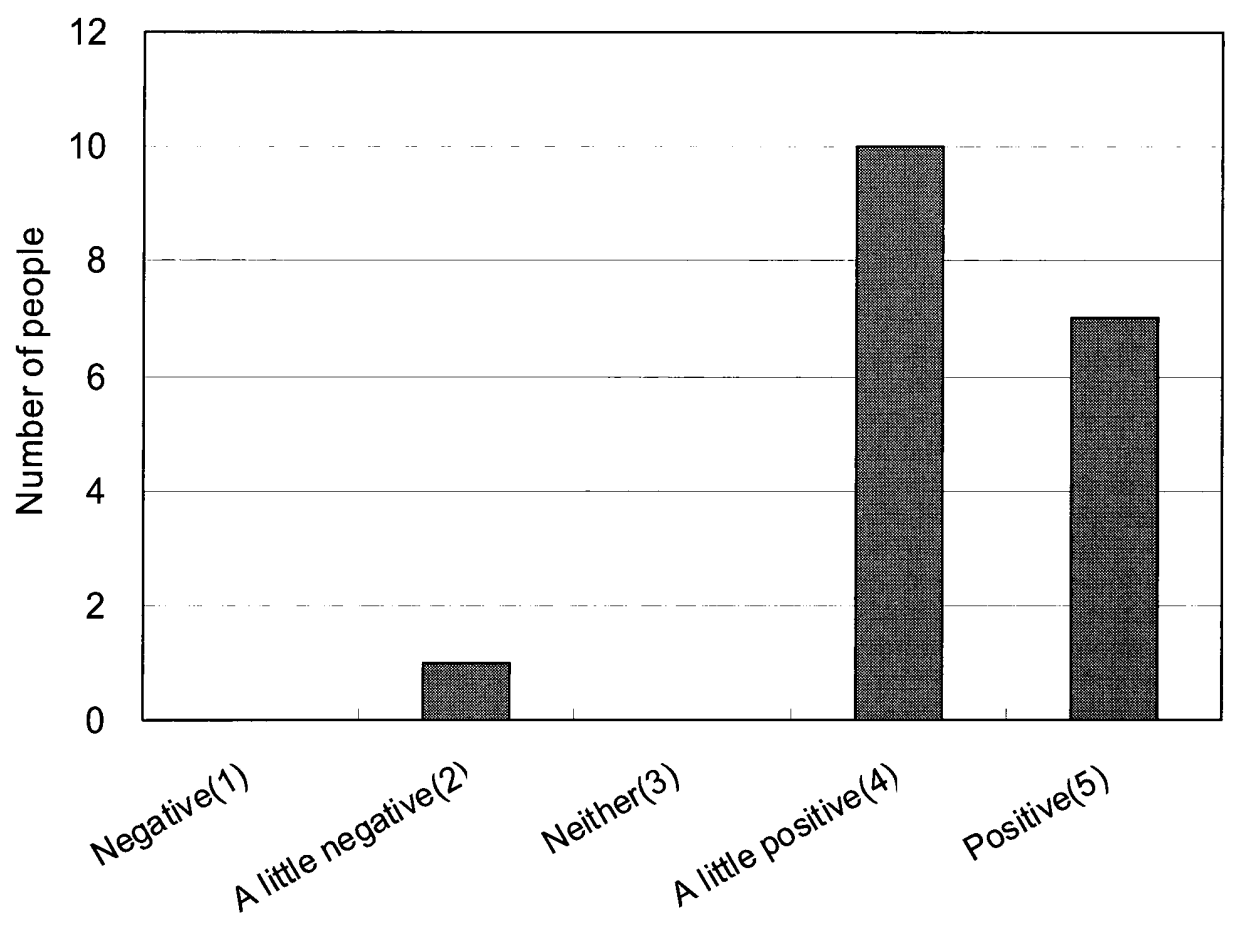

Fig.10 The recognition of students for elderly people

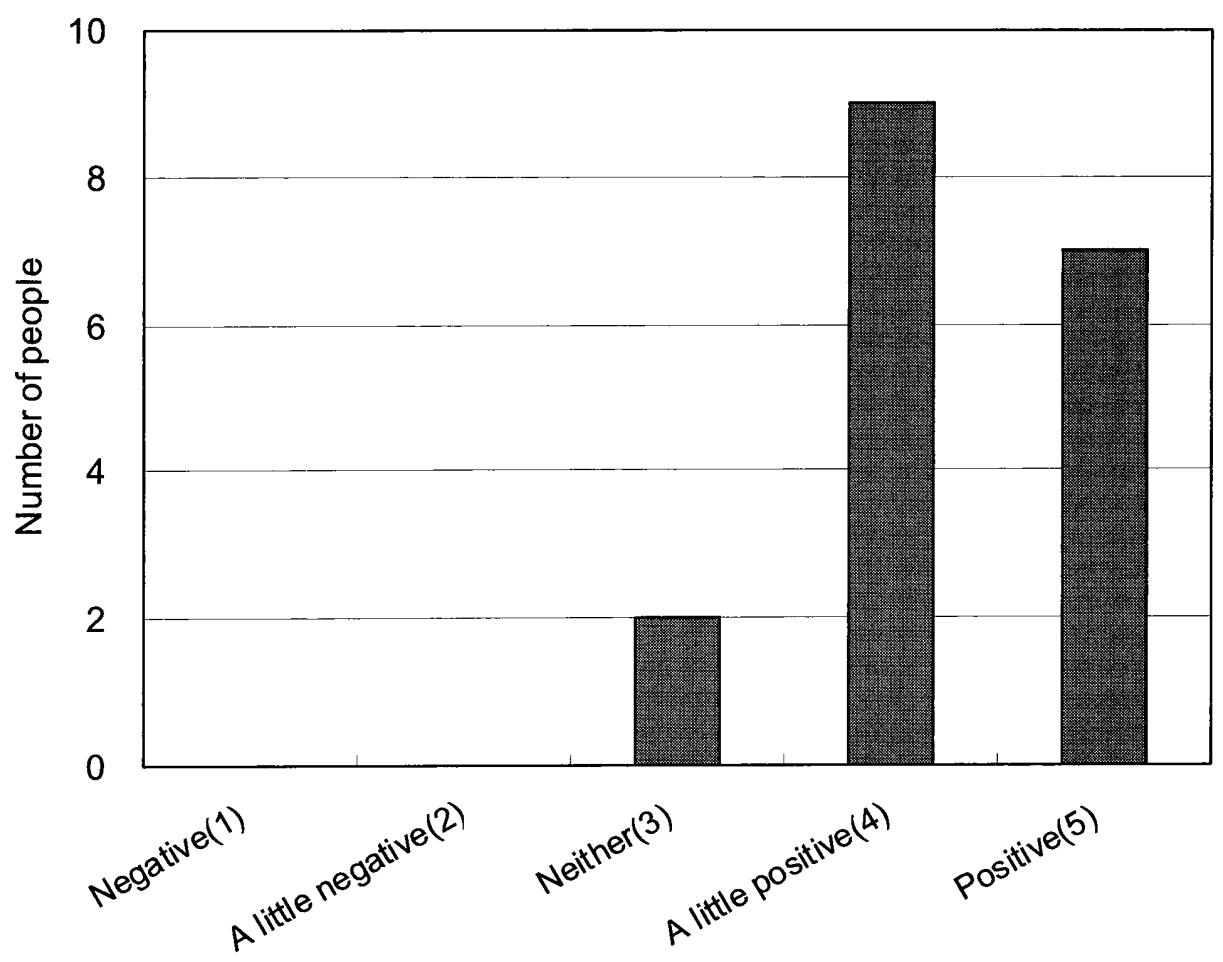

Fig.11 The impression of the elderly participants for the students and the school 


\section{Conclusion}

As the number of elderly is growing in Japan, to increase and keep the number of healthy elderly, who are able to spend life without difficulties, is a huge benefit not only for those elderly but for the whole society.

The results of this report are bellows.

1) The trainings to improve the body balance had positive effects on walking ability.

2) Students who volunteered gained the valuable opportunity to communicate with the elderly and acquired better understanding to elderly and people with handicap.

3) The survey results showed the participants' mental satisfaction also enhanced.

Overall, we are certain that valuable experience was gained both by the students and the elderly who participated to the classes. Hence, we think that it is vital to give this kind of experience to more students as a part of engineer education.

\section{References}

(1) Population Statistics of Japan 2008, The National Institute of Population and Social Security Research, http://www.ipss.go.jp/site-ad/index_english/

(2) Daitoh,T., Kono,G., Nishimura,A. and Noda,N., Nursing-Care Prevention of Kisarazu shi, The 10th Annual Meeting of Japan Society for Welfare Engineering (in Japanese), (2008), pp.28-29.

(3) Daitoh,T., Kono,G., Kuroda,T., Kanetsuna,M., Nishimura,A. and Noda,N., Enforcement of the Nursing-Care Prevention and the Educational Effect on Kisarazu National College of Technology, Journal of Japanese Society for Engineering Education (in Japanese), Vol.57, No.4, (2009), pp.86-91.

(4) Robert C. and Brian J. G., Technique Systems in Chiropractic, Churchill Livingstone, (2004), ISBN-10: 443074135.

(5) Scott Haldeman, Principles and Practice of Chiropractic, McGraw Hill Medical, (2004), ISBN-10: 0071375341. 